\title{
Disabled Friendly Facility between Feasibility and Legality
}

\author{
Ibrahim Z. Baghdadi ${ }^{1}$, Mohammad Fahes ${ }^{2}$, Muhieddine Z. Ramadan ${ }^{3}$ \\ ${ }^{1}$ Lebanese University, Faculty of Tourism, Lebanon \\ ${ }^{2}$ Fulcrum, Department of Finance and Quality Management, Lebanon \\ ${ }^{3}$ Lebanese International University, Chairperson of Management and International Management Department, Lebanon \\ Correspondence: Ibrahim Z. Baghdadi, Lebanese University, Faculty of Tourism, Lebanon.
}

Received: July 28, 2017

Accepted: August 14, $2017 \quad$ Available online: August 24, 2017

doi:10.11114/aef.v4i5.2558

URL: https://doi.org/10.11114/aef.v4i5.2558

\begin{abstract}
Most hotels in Lebanon, built before 2011, do not provide access to disabled persons in light of 220/2000 law. This is due to: 1/ a misconception that a Disabled Friendly Facility (DFF) would be on behalf of hotel guests' satisfaction and consequently, would reduce hotel's popularity and revenue; $2 /$ a fear that the unforeseen demand for DFFs will be offset by expenses and, in best-case scenarios, would not generate enough profits to pay back initial investments. In brief, hotel-business investors are not sure about the convenience of a DFF and about the number of DFFs to provide in light of 7194/2011law. The objective of this paper is, on the first hand, to demonstrate the financial feasibility and the economic convenience of a DFF and, on the other hand, to test its impact on the satisfaction of hotel guests. In other terms, on the popularity of the hotel.
\end{abstract}

Keywords: disabled friendly facility, hotel, law, financial feasibility, economic profit, revenue management

\section{Introduction}

The word disability is commonly related to the inability of a person to carry out his day to day activities (Hausman, 2015). Being physical or mental, disability is considered as the main obstacle behind the incapacity of a person to access a private or public facility (Connolly, 2004). In Lebanon, the unsatisfactory construction laws and guidelines that define accessibility requirements paired with the unsuitable infrastructure, have deprived people with disability to blend into society. What added the cherry on the top with this unpleasant situation is the reluctance of local authorities in enforcing the laws, although unsatisfactory, that support the national rights of disabled persons (Raif, 2011).

A review of Lebanese laws and decrees related to the accessibility of disabled persons to hotels and restaurants revealed three main deficiencies: $1 /$ a set of incomplete rules and standards that do not satisfy the actual needs, 2/the ambiguity of some rules, 3/a set of inadequate rules and guidelines that do not take into consideration the existing layout and design of a hospitality establishment. Going back to the roots of the problem, these deficiencies are directly related to the conflict of power that exists between ministries and governmental bodies concerned with layout \& design standardization and formulation (Wau, 2015), what impedes any serious formulation and implementation of laws.

Beside the insufficiency, inadequacy and ambiguity of laws, as well as, the reluctance in enforcing these laws, the absence of a clear perception about the positive impacts (financial and economic) of a Disabled Friendly Facility (DFF) on business struggles most hotel owners between: 1/ the possibility of providing a DFF that satisfies the needs of disabled guests while assuring a fair return on investment, 2/ maintaining regular-guests' satisfaction that could be affected due to altering hotel's layout and design in order to fit the disabled community.

In an attempt to justify the convenience of a DFF, in terms of profitability and popularity, this research paper studies, on the first hand, the financial and economic feasibility of a DFF in light of the requirements of the presidential decree law 7194/2011. On the other hand, this research paper examines the acceptance of hotel regular guests to stay in a DFF, more precisely in a guest room (with its related facilities), in an attempt to jettison the fallacy of hotel owners related to guest dissatisfaction and business loss.

Undoubtedly, a DFF would increase the satisfaction of guests with physical disability (Yoh, Mohr, \& Gordon, 2008). The hypothesis that this paper seeks to justify is whether a DFF will be convenient to hotel owners (in terms of profitability and popularity) and their guests (in terms of satisfaction). This paper tries to justify that providing a DFF 
would allow hospitality establishments to acquire a new clientele whose demand, when added to the demand of regular guests, will assure a fair return on investment without sacrificing regular guests' satisfaction. The study of the financial feasibility and the economic convenience of a DFF for hospitality establishments is based on the concepts of Return on Investment (ROI), Price Differential and the economic concept of supply and demand, whereas the valuation of the convenience for regular guests (non-disabled) to stay in a DFF is based on an empirical study.

\section{Disability in Lebanon and the Limitations of Legislation}

Physical and mental impairments are the major types of disability found in Lebanon. According to Alberta Human Rights Commission [AHRC] (2012, p. 1) : "Physical disability is defined in the Act as any degree of physical disability, infirmity, malformation or disfigurement that is caused by bodily injury, birth defect or illness. This includes, but is not limited to, epilepsy; paralysis; amputation; lack of physical coordination; visual, hearing and speech impediments; and physical reliance on a guide dog, service dog, or a wheelchair or other remedial appliance or device. Mental disability is defined in the Act as any mental disorder, developmental disorder or learning disorder, regardless of the cause or duration of the disorder".

In the same vein, the Americans with Disabilities Act (ADA) of 1990 defines the term "Disability" by: "An individual has a physical or mental impairment that substantially limits one or more of his/her major life activities or there is a record of such an impairment or an individual is regarded as having such an impairment."

As for the Lebanese law 220/2000, it defines in article number two a disabled individual by: "A person whose capacity to perform one or more vital functions, independently secure his personal existential needs, participate in social activities on an equal basis with others, and live a personal and social life that is normal by existing social standards, is reduced or non-existent because of a partial or complete, permanent or temporary, bodily, sensory or intellectual functional loss or incapacity, that is the outcome of a congenital or acquired illness or from a pathological condition that has been prolonged beyond normal medical expectations".

Based on the definition of 220/2000 law, approximately 10 percent of Lebanon's population was considered disabled in 2013 (Anderson, 2013). As part of its responsibilities, the Lebanese Ministry of Social Affairs started issuing, as of 1990s, Disability-Identification Cards to those satisfying the criteria stipulated by the law. The total number of registered disabled until the end of January 2013 was only 80,703 (equivalent to $18 \%$ of the total disabled population in Lebanon (The United Nations Educational, Scientific and Cultural Organization [UNESCO], 2013).

Table 1 . Distribution by type of disability

\begin{tabular}{ccc}
\hline Form of disability in Lebanon & Number & Percentage \\
\hline Physical & 48288 & 53.76 \\
Mental & 24656 & 27.45 \\
Hearing & 7808 & 8.65 \\
Visual & 6886 & 7.67 \\
Learning & 2185 & 2.43 \\
\hline
\end{tabular}

Source: (UNESCO, 2013)

Talking about the law 220/2000, it defines the rights of people with disabilities to education, rehabilitation, employment, and access to services. According to article 33 of this law, every disabled person has the right of accessibility, what implies that all buildings, public and private facilities, should apply the engineering specifications and standards that facilitate this access. Regretfully, until the moment, the Lebanese Ministry of Social Affairs has not been able to enforce this law due to the lenience of the Lebanese Ministry of Tourism in allowing inept hospitality establishments ${ }^{1}$ to operate based on a preliminary authorization ${ }^{2}$.

Consequently, most hotels, restaurants and other hospitality organizations in Lebanon have ignored the law and have been operating based on a preliminary authorization that does not guarantee the minimum standards of food safety, sanitation and accessibility to disabled persons. As a result of this deficiency, accessibility of the most vulnerable citizens was limited to a few number of five-star-hotels and restaurants (particularly international) that are financially capable to obtain the official authorization from the Ministry of Tourism and have espoused their own international standards of facility layout and design for the service of disabled persons.

\footnotetext{
${ }^{1}$ By inept we mean, haven't satisfied the minimum requirements for disabled accessibility.

2 The preliminary authorization is a written authorization given by the Ministry of Tourism to entrepreneurs who wish to start a hospitality business. This authorization has no time frame and allows its holder to start operation, by the time he completes the rest of requirements (Municipality and Ministry of Health requirements) in order to get the official authorization that entitles him to operate a food establishment.
} 
In 2010, the Ministry of Tourism in Lebanon has elaborated, in collaboration with a consultant group (Bureau Veritas), the new Lebanese code for hotel and restaurant classification which has been criticized later on by the Ministry of Social Affairs, the Lebanese Physical Handicapped Union and other NGOs (LPH, etc.) for ignoring the suggestions of 220/2000 law.

Knowing that hotel and restaurant classification in Lebanon ranges from one to five stars, this classification is based, according to the new Lebanese code for hotel and restaurant classification, on 94 standards for restaurants and 302 standards for hotels. It is surprising to find out that just two criteria of classification, from this new code, are related to accessibility of disabled individuals (hotel classification criteria number 59 related to the minimum numbers of rooms required for disabled according to hotel size, and restaurant classification criteria number 36 related to the passageway to the dining room). Obviously, the deficiency of this new code has widened the gap between former and recent engineering specifications, considered as a framework for accessibility designs, and deprived disabled individuals to access hotels and restaurants.

Criticism to the Code of Hotel and Restaurant Classification in Lebanon:

- Hotel criteria number 59: “... accessibility of the hotel through a ramp or other ways, and entry to people with special needs on wheel chair to a fixed number of rooms" (Ministry of Tourism [MOT], 2010). This criteria is insufficient to ensure full accessibility of persons with disability, of all types, to hotel facilities.

- Hotel criteria number 59 applies to new hotel projects (licensed after 2010), while being optional for existing ones (licensed or not before 2010).

- Restaurant criteria number 36: "Entry of disabled people (on a wheelchair) to the restaurant (ramp, door, elevator, etc.)..., existing institutions should provide a special lane for disabled movement to enter the restaurant" (MOT, 2010). This criteria applies to new restaurants only (licensed after 2010) while being optional for existing ones (licensed or not before 2010), and concerns the physical disability only.

- Restaurant criteria 36 is limited to the description of the passageway that restaurants should provide for disabled persons, with no indication to the other important considerations such as: toilet space, layout and design, elevators' design and control panel, aisle spaces, etc.

The triviality in enforcing barrier-free laws and the reluctance in amending the content of the latest code have encouraged hotel owners to avoid any investment in a DFF. Furthermore, most hotel owners consider that adjusting hotel design, to fit disabled guests would, on the first hand, disturb regular hotel guests and reduce the popularity of the establishment and, on the other hand, it will incur an unnecessary cost that cannot be easily paid back.

\section{The Necessity for a Disabled-Friendly-Facility}

People with disabilities have often been denied access to hospitality organizations in Lebanon due to the lack of physical accessibility or due to their disabilities. In both cases, guests with disability have all the rights to access any hospitality organization and any public facilities for entertainment purposes. According to Brennan (2013), once the needs of the disabled community are clearly identified, we can suggest regulations that identify the barriers and mention priorities for their removal (for example: provide access to any establishment from public sidewalks, public transportation and parking area, provide access to the goods and services, provide access to public toilets and remove barriers to other amenities offered to the public).

One may consider that the ideal barrier-free design ought to satisfy, beside the basic humanitarian needs, the rest of Maslow's pyramid of needs (security, social, self-actualization and fulfillment) for this vulnerable community. As part of its role to support humanitarian needs around the globe, the UN suggested in 2003 a design manual for a barrier free environment. This manual suggested some revised architectural design standards that should facilitate accessibility to disabled individuals. In Lebanon, the presidential decree law 7194/2011 comes in conjunction with the law 220/2000. It represents a design manual that guides hospitality organizations to provide a suitable environment for disabled guests (accessibility to corridors, main entrance, doors, elevators, stairs, rooms, kitchens and toilets).

The demand for a DFF is not recent, the ADA has voted earlier for a "Reasonable Accommodation" that implies changes in favor of disabled guests without disturbing, neither the party making them, nor the in-house guests. For it, the United Nations Economic and Social Commission for Western Asia (ESCWA) suggested to the Lebanese government in early 1994 ( 3 years after conflicts in Lebanon ended) a set of engineering standards which facilitate the accessibility of disabled persons to public and private facilities. Whomever the regulator is, the engineering standards should respond to the needs of the disabled community, therefore one should question about the integration of representatives of this community in formulating the laws and in setting the engineering guides for hospitality organization 


\section{The Minimum Requirements for Physical Accessibility of People with Disabilities}

Any person may unexpectedly become physically disabled, children, elderlies, people with broken legs, people who had surgeries in eyes and ears etc. It is necessary that people who become disabled continue to live a normal life, this is possible only if public and private establishments remove all barriers and provide the minimum requirements for physical accessibility (Richard H Penner, 2012).

As accessibility is not limited to physically accessing an establishment in a wheelchair, it requires the set-up of a suitable environment to everyone, including disabled persons. According to the presidential decree law number 7194/2011, a suitable environment should consist of:

1. Ramps: maximum ramp slope is $12 \%$, Maximum length is $2 \mathrm{~m}$, ramps should be provided with landings for resting every $20 \mathrm{~m}$, at every change of direction and at the top and bottom of every ramp. The landing should have a minimum length of $1.40 \mathrm{~m}$ and a minimum width equal to that of the ramp.

2. Corridors: the width of a corridor should not be less than $0.90 \mathrm{~m}$, the width of a public corridor should not be less than $1.80 \mathrm{~m}$ and its height should not be less than $2 \mathrm{~m}$.

3. Parking: length of $5.20 \mathrm{~m}$, width of $3.6 \mathrm{~m}$ if the parking is at a $45^{\circ}$ angle with the passage. In total, hotels should provide $1.5 \%$ of parking capacity to disabled guests.

4. Doors: the minimum opening is $0.90 \mathrm{~m}$ when the door is open. The space in front of the main gate should not be less than $0.2 \mathrm{~m} \times 0.25 \mathrm{~m}$.

5. Stairs: the minimum width of a stairway should be $0.80 \mathrm{~m}$. As for landing, an intermediate landing should be provided when the stairs cover a difference in level of more than $2.50 \mathrm{~m}$. The length of the landing space should be at least $1.50 \mathrm{~m} \times 1.40 \mathrm{~m}$.

6. Elevators: the minimum internal elevator dimensions, allowing for one wheelchair passenger alone are $1.10 \mathrm{~m} \mathrm{x}$ $1.40 \mathrm{~m}$. The door opening should not be less than $0.80 \mathrm{~m}$, the resting space in front of the elevator should not be less than $1.4 \mathrm{~m} \times 1.8 \mathrm{~m}$, the panel should be $0.9 \mathrm{~m}$ above the floor, elevators should be supplied with voice assistance.

7. Room facility: room width should not be less than $3 \mathrm{~m}$ for disabled persons with total dimensions of not less than $11.5 \mathrm{~m}^{2}$. According to Jonitas Davis (2012), the number of beds, the size of the rooms and the amenities offered are the main criteria for hotel classification.

8. Kitchenette: the width of kitchenette provided in a disabled room should not be less than $2.5 \mathrm{~m}$ with a minimum dimension of $8 \mathrm{~m}^{2}$.

9. Restrooms: the dimension of a disabled restroom in dorms and furnished apartments should not be less than $2.50 \mathrm{~m} \mathrm{x} 3 \mathrm{~m}$ and $2.50 \mathrm{~m} \times 2.5 \mathrm{~m}$ in a public establishment. Assistance handles should be fixed $0.9 \mathrm{~m}$ above the floor.

\section{The Convenience of a DFF for Hospitality Establishments}

From a financial perspective, a project is considered feasible if it assures a convenient and a continuous return on the initial investment and pays back shortly. According to Scott (2003), the return on investment, also called "Rate of Return" or "return on assets" is a measure of net income that a firm is able to earn with its total assets. As for Guinan (2009), the ROI is a performance measure used to evaluate the efficiency of an investment or compare the efficiency of a number of different investments. The financial convenience reflects a positive return for investing in a DFF. By justifying the ability of a DFF to generate a convenient net income that pays back the initial investment in a short period, the efficiency of this investment is justified (sufficient income and low financial threat) and its viability for hospitality establishments is ascertained.

From an ethical and a social standpoint, although price discrimination is not restricted by law ${ }^{3}$, the scenario that was adopted in this study is a Straightforward Single-Price Scenario, a term utilized by economists to describe this behavior. The most straightforward form of single-price scenario consists of charging different customers the same price for access to the same service or product. A more refined form consists of charging different customers the same price that allows them to access different versions of the same product or service, even if the costs of the versions are different. For Fisher (2007, p. 26), “...if a social or economic practice makes people unhappy or angry, the resultant disutility must be considered in determining whether the practice of balance promotes social welfare. Thus, in determining whether a particular form of price discrimination advances social welfare, one must take into account the extent to

\footnotetext{
${ }^{3}$ Based on the economic approach of "price discrimination", known in marketing as "differential pricing".
} 
which members of the society (and not just potential purchasers of the good or service in question) believe that the practice is exploitative or unfair ${ }^{4}$ ".

\subsection{Hotel Design and Rooms for Disabled Guests}

Hotel classification in Lebanon follows the code of the Ministry of Tourism (prepared by Bureau Veritas ${ }^{5}$ ). As previously mentioned, this code is prejudicial to the disabled community in Lebanon and does not respond to the conditions of the articles $33 \& 34$ of the $220 / 2000$ law, related to the rights of disabled people for accessibility. Moreover, this code does not assure the implementation of article 13/1 from the Lebanese construction law number 646/2004. In an attempt to fill the gaps in this code, the Ministry of Tourism has encouraged newly constructed hotels in Lebanon to apply the construction guidelines of the presidential decree law number 7194/2011. This latest decree law is a tailored combination of the ADA and the Guide for Construction Designs for a Barrier-Free Environment of the Ministry of Social Affairs. The aim is to provide general construction guidelines that hospitality organization in Lebanon ought to follow in compliance with article 34 of 220/2000 law and article 13/1 of 646/2004 construction law.

On the other hand, the construction guidelines stipulated by the presidential decree law 7194/2011 concern all newly constructed buildings, whether private or public, designated for public utilization (like, but not limited to: public organizations and institutions, offices, mosques and churches, shopping areas which are less than $150 \mathrm{~m}^{2}$, hospitals and clinics, entertainment centers, tourism establishments, sport clubs, ports and airports, as well as the private residential buildings). According to the presidential decree law, for the newly constructed hotels (as of 2011), disabled guestrooms should not count less than $5 \%$ of a hotel's total capacity and construction specifications must comply with the guidelines of the law. Regretfully, old hotels and other hospitality facilities that were constructed before 2011 have been exempted from this law, but still entitled to a 6-year grace period during which they can benefit from a reduced rate on redesigning or reconstructing investments.

Based on the construction guidelines of the presidential decree law 7194/2011, the responsibility of newly constructed hotels is limited to providing, in addition to the $5 \%{ }^{6}$ of their total capacity, an external (outdoor ramps, parking area, rumps) and an internal accessibility (rumps, corridors, entrance, stairs, elevators, doors) to disabled guests. For old hotels (built before 2011), redesigning or reconstructing costs will normally reduce profits in the short run unless the expected total revenue resulting from an increase in demand can absorb the total cost and leave a fair economic profit ${ }^{7}$. However, in the long run, when the cost of improvements is completely covered, profits will increase automatically.

At the end, as part of its objective, this paper will attempt to convince hotel owners to provide a DFF due to its financial and economic convenience, in light of law.

\subsubsection{The Normal Rate of Return for Hotel Owners on Investing in a DFF}

When hotel owners decide to invest in a DFF, necessary resources should be allocated to satisfy the requirements of the presidential decree law 7194/2011, but, at the same time, a fair rate of return should be generated. At this point, it is relevant to distinguish between the rate of return and the normal rate of return. As for the rate of return, it is the annual flow of net income generated by a DFF, expressed as a percentage of total investment. Whereas, the normal rate of return is the rate that is just sufficient to keep owners and investors satisfied. According to Case, Fair \& Oster (2007), a normal rate of return is considered a part of the total cost of business. When a firm earns a normal rate of return, it is earning a zero profit. If the level of profit is positive, the firm is earning an above-normal rate of return on capital.

Knowing that the hotel business is seasonal, the challenge for hotel management is to provide a steady return that keeps hotel owners satisfied. An objective that may not be achieved without disbursing, substantially, a rate of return that is higher than the interest rate that owners would gain if they would have invested in risk-free government bonds.

\footnotetext{
${ }^{4}$ For example, as Frank Michelman showed long ago, an interpretation of the "takings" doctrine that aspires to maximize allocative efficiency must take into account the "demoralization costs" arising out of the dismay experienced by persons who witness uncompensated governmental regulations of private property and believe them to be unjust. See Frank Michelman, "Property, Utility, and Fairness: Comments on the Ethical Foundations of 'Just Compensation' Law," Harvard Law Review 80(1967).

${ }^{5}$ Based on Ministry of Tourism Decision No. 16 dated 12 January 2011.

${ }^{6}$ Hotels constructed as of 2011 should provide $5 \%$ of their lodging capacity to disabled-guests. This percentage is not fix, it is a scale that is based on hotel capacity. ( Refer to appendix 1)

${ }^{7}$ Economic profit is the difference between total revenue and total economic cost (out of pocket cost +opportunity cost of all factors of production).
} 


\subsection{Cost of Investment}

Investment costs in a DFF denote the engineering work (construction and improvement costs as per the presidential decree law 7194/2011) including the price of materials and wages. This cost is calculated independently from hotel type (resort, business, etc.), hotel size (large, boutique, etc.) or hotel classification (number of stars, services and facilities, etc.).

\subsubsection{Construction and Improvement Costs Include}

Outdoor costs:

The construction standards designated by the presidential decree law regarding the outdoor area are uniform for all hotel types. Based on these standards, the cost of outdoor constructions/improvements should consider: outdoor ramps, parking area and signs.

\section{Indoor costs}

The cost of indoor construction and improvements varies according to facility size, type, classification, location, etc. We mean by indoor investments, the expenses of installing and constructing the engineering requirements of the presidential decree law 7194/2011, namely: rumps, corridors, entrance, stairs, elevators, doors, guest room, kitchenette and toilets.

\subsection{The "Total Analysis" for Determining the Optimal Output Level}

From an accounting perspective, the optimal output level can be determined easily by using the total revenue (TR) total cost (TC) approach. If TR-TC is equal to total profit, then the optimal output level is the one that provides the highest total profit.

In calculating the total revenue, we will designate by " $P$ " the room rate and " $Q$ " the total number of rooms demanded. Based on the single-price scenario (without discrimination) adopted in our study, the price of a DFF is the same as a regular-room, independently from construction and improvement costs. Accordingly, the total revenue for selling $Q_{1}$ regular rooms is: $T R_{1}=P \times Q_{1}$.

The creation of DFFs is supposed to increase the demand for hotel rooms from $Q_{1}$ to $Q_{2}$, the new total revenue becomes then: $T R_{2}=P \times Q_{2}$.

Assuming that:

- $Q_{1}$ is the total number of Regular Rooms demanded in a hotel.

- $Q_{2}$ is the total number of Rooms Demanded in a hotel (Regular Rooms and DFFs).

- $y_{x}$ is the total number of DFFs demanded in $x$ years $\left(y_{x}=Q_{2}-Q_{1}\right)$.

- $\quad P$ is the room rate (Regular Room or DFF).

- $T R_{R}$ is the total revenue generated from selling Regular Rooms.

- $T R_{T}$ is the total revenue generated from selling Regular Rooms and DFFs.

- "a" represents the variable cost of operating a hotel room.

- "b" represents the cost of construction \& improvements of a DFF (fixed cost), including the indoor and outdoor costs.

- The demand curve is linear.

- All hotel rooms, including DFFs, are of the same category (standard rooms).

- The hotels operate in a perfectly competitive market and, therefore, are price takers.

- The DFF maintains its value over time.

The conversion of standard regular rooms into DFFs, the establishment of related disabled facilities and the provision of accessibility should increase the demand for DFFs by the disabled community from $Q_{1}$ to $Q_{2}$ (Figure 1 ) while the room rate will remain unchanged. This could be graphically represented by a right shift of the demand curve.

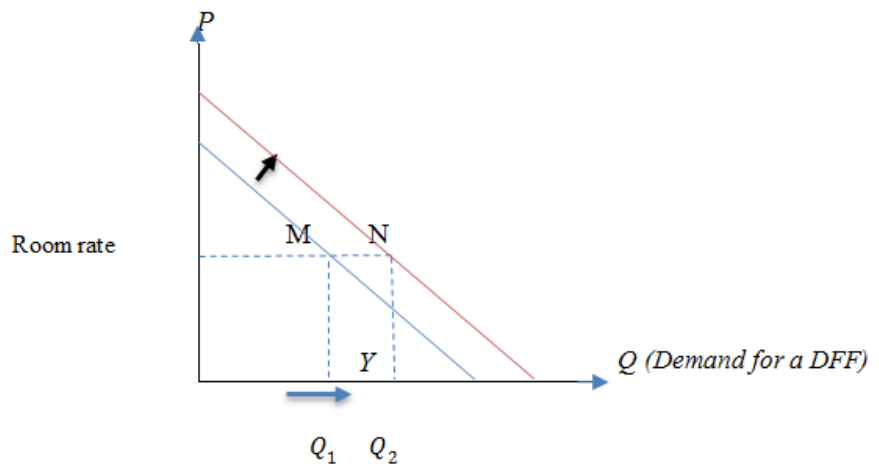

Figure 1. The right shift of the demand curve for DFFs 
The study of the viability of DFFs for hotel business requires then a preliminary estimation of demand for DFFs and an analysis of that demand in light of the relevant investment costs and contribution margin.

In terms of total revenue:

$$
\begin{aligned}
& T R_{R}=P \times Q_{1} \\
& T R_{D F F}=P \times y_{x} \\
& T R_{T}=P \times Q_{2} \\
& =P \times\left(Q_{1}+y_{x}\right) \\
& =T R_{R}+P y_{x} \\
& =T R_{R}+T R_{D F F}
\end{aligned}
$$

Hence,

$$
T R_{T}=T R_{R}+T R_{D F F}
$$

In terms of total cost:

Total cost $(\mathrm{TC})=$ Fixed costs $(\mathrm{FC})+$ Variable costs $(\mathrm{VC})$

$T C_{T}=(\mathrm{FC}$ of a regular room + DFF investment cost $)+($ total demand $\mathrm{x}$ unit variable cost $)$

$$
\begin{aligned}
& =\left(F C_{R}+\mathrm{b}\right)+\left(Q_{2} \mathrm{x} a\right) \\
& =\left(F C_{R}+\mathrm{b}\right)+\left(Q_{1}+y_{x}\right) \mathrm{x} \mathrm{a} \\
& =F C_{R}+\mathrm{a} Q_{1}+\mathrm{a} y_{x}+\mathrm{b} \\
& =T C_{R}+T C_{D F F}
\end{aligned}
$$

Hence,

$$
T C_{T}=T C_{R}+T C_{D F F}
$$

In terms of profit:

To decide on the number of DFFs to be provided, one should start with the calculation of the minimum number of DFFs that should be sold to break even, and to compare this number to the estimated demand for DFFs. If the estimated demand exceeds the minimum required, the provision of DFFs will be pertinent.

Total profit $\left(\Omega_{T}\right)=$ Total Revenue $\left(T R_{T}\right)-$ Total Cost $\left(T C_{T}\right)$

$$
\begin{aligned}
& =T R_{R}+T R_{D F F}-T C_{R}-T C_{D F F} \\
& =\Omega_{R}+\Omega_{D F F}
\end{aligned}
$$

Hence,

$$
\Omega_{D F F}=\Omega_{T}-\Omega_{R}
$$

Assuming that $\Omega_{R}$ is positive. In order to generate a sufficient total profit, $\Omega_{D F F}$ should be also positive.

If $\Omega_{D F F}>0$, then:

$T R_{D F F}-T C_{D F F}>0$

$P y_{x}-\left(a y_{x}+b\right)>0$

$y_{x}(p-a)>b$

$y_{x}>\frac{b}{P-a}$

Hence,

$$
y_{x}>\frac{b}{C M}
$$

Putting aside the ethical and corporate social responsibility, the creation of a DFF requires that the estimated demand (in currency value) for DFFs in $x$ years $\left(y_{x}\right)$ exceeds the value of investment costs divided by the contribution margin, otherwise a hotel will incur losses. 
Nevertheless, due to perfect competition, hotels have no control neither on room rates nor on demand and there might be times when the room rate does not fully cover the unit variable cost of operating a DFF. Consequently, a hotel should assess the extent of its losses to the alternative of providing a very limited number of DFFs in order to remain in the market with the expectation of better times ahead. In the short run, the incurred losses could be justified by the fact that certain costs must be borne regardless of whether the hotel operates. However, in the long run, if losses persist, hotel owners should eventually reconsider the provision of DFFs and may convert them back into regular rooms ( i.e. in case hotel regular guests refuse to stay in a DFF) or to any other revenue center (i.e. meeting room, outlet, business center, etc.).

\subsection{The Economic Convenience}

The economic convenience is the ability of a firm to earn an "Economic Profit" in the long run. Whenever resources are invested in a business, there is an opportunity cost. In the same vein, instead of investing their retained earnings in a DFF, hotel owners could earn interest on those funds. From an economic point of view, a hotel breaks even when its accounting profit equals its opportunity cost, any amount in excess of the out-of-pocket cost plus the opportunity cost of running a DFF is an economic profit.

In the following, we will formulate the economic profit for DFF providers by considering the normal rate of return (i.e. the rate of interest that hotel owners could have received by purchasing Treasury bonds) as being part of their total economic cost.

Assume that:

- "a" is the variable cost of operating a hotel room.

- "b" represents the necessary investment costs to provide a DFF along with accessibility to disabled (indoor and outdoor construction and improvement costs).

- $\quad \mathrm{r} \%$ the normal rate of return 8 .

- DFF maintains its value over time.

- $y_{x}$ is the number of DFFs demanded in $x$ years.

- Hotels operate in a perfectly competitive market.

The consideration of opportunity cost in the calculation of total economic cost leads us to calculate the economic profit.

$$
\begin{aligned}
E \Omega_{D F F} & =T R_{D F F}-T E C_{D F F} \\
& =T R_{D F F}-\left(T C_{D F F}+\text { opportunity cost }\right)
\end{aligned}
$$

Knowing that construction \& improvement costs are not a direct part of the cost of a hotel, the only real cost is the forgone interest on the necessary investment costs (indoor and outdoor construction and improvement costs), which is $\mathbf{r}$ $\mathbf{x}$ b.

Consequently,

$$
E J_{D F F}=T R_{D F F}-\left[\left(a y_{x}\right)+(r * b / 100)\right]
$$

When a DFF earns a positive profit, it is earning more than is sufficient to retain the interests of hotel owners. This task is not easy as strategic decisions towards environmental changes could be immediate (short run) or adjusted with time (Long run). In the short run, hotels operate under a fixed scale whereas in the long run, there are no fixed factors of production and new hotels can freely enter while existing hotels can freely exit the market of DFF. Whatever the decision is, the final objective of any hotel business remains profit maximization.

On the other hand, the product development strategy (a DFF is considered a new product to existing market) inquires answering the following questions:

- How many DFFs should be provided?

- If we provide this number, how much profit would be earned?

- If a loss rather than a profit is incurred, will it be worthwhile to continue in this market in the long run (in hopes that a profit will be earned) or not?

Referring to the total-analysis approach, the optimal output level is the one that maximizes the difference between total revenue and total cost. In the economic approach the determination of the optimal output is based on the calculation of marginal revenue and marginal cost instead of total revenue and total cost. Hence, to maximize profit, a hotel should "produce a level of output at which the additional revenue received from the last unit is equal to the additional cost of producing that unit. In short, MR=MC (Marginal Revenue = Marginal Cost)" (Keat \& Young, 2009, p. 67).

\footnotetext{
${ }^{8}$ The annual r\% in Lebanon is 5.45\% on Euro bonds (BLOM, 2016).
} 
Being a price taker, a hotel can sell whatever quantity it wishes of DFFs at the market-determined price. Knowing that: 1/ marginal cost changes as the quantity produced increases (first, marginal cost declines as the quantity produced increases but then marginal costs start to increase, causing diminishing marginal returns), 2/room supply is limited to hotel capacity and availability (remember that the ratio of DFF by law is around 5\% in Lebanon), it is uncommon to obtain an increasing marginal returns on sales of DFFs in Lebanon.

Normally, if the quantity supplied of DFFs is where marginal revenue is greater than marginal cost, then, it is to the benefit of the hotel to supply more DFFs due to the resulting economic profit (Figure 2). However, the behavior of hotels in Lebanon reflects a limited supply of DFFs, this could be explained by a marginal cost that is greater than the marginal revenue (Figure 3).

With this in mind, it is possible that this limited supply increases profits when the reductions in marginal cost exceeds the reductions in marginal revenue. Finally, the firm's profit-maximizing choice of output will occur where Marginal Revenue equals Marginal Cost.

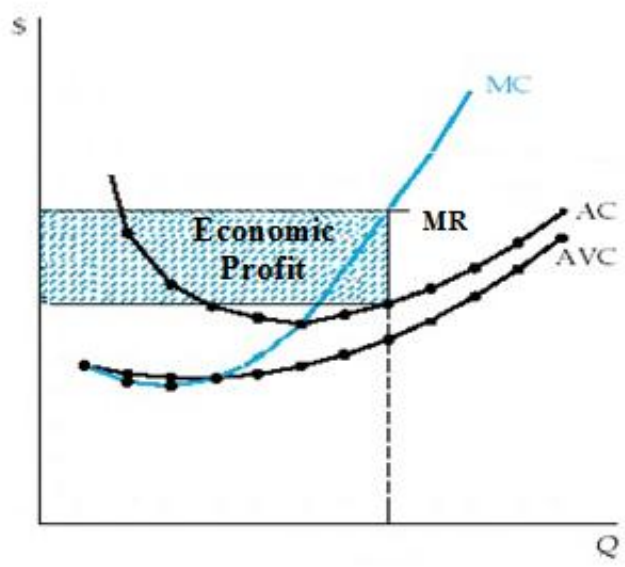

Figure 2. Economic Profit

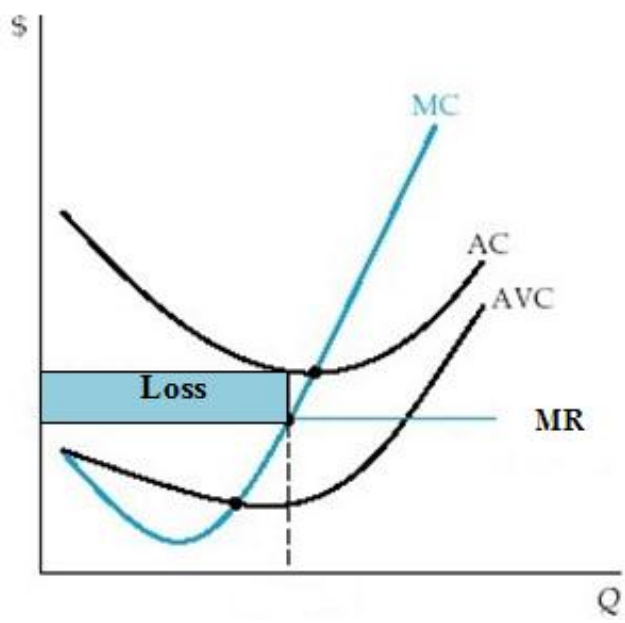

Figure 3. Economic Loss

Knowing that, in the long run, hotels would have the ability to modify their fixed factors of production, a hotel that is making losses in the long run due to low demand for DFFs should then consider converting its DFFs into regular rooms even if they are generators of positive contribution margins.

Comparing the long run to the short run influence on market price, the economic theory states that: whether the market price in the short run is capable to yield profit or loss for DFF providers, it will settle at a point where these providers earn a normal profit. Accordingly, the room rate that enables DFF providers to earn above-normal profit, in the long run, would encourage other DFF providers to enter the hospitality market, causing thereby, a decrease in market price (right shift of supply curve). Subsequently, room rates below the normal level would cause DFF providers to leave the market and lead to an increase in market price (left shift of the supply curve). 


\section{The Acceptance of a DFF by Hotel Guests}

The economic and financial convenience of DFFs for hotel owners shouldn't be obstructed by a rejection of this facility by hotel guests. The necessity to assess the acceptance of hotel guests to stay in a DFF stems from the fact that the development of DFFs will incur changes not only to guestrooms but also to public areas (hotel internal and external design), risking thereby to affect the satisfaction of hotel guests and to decrease sales.

In an attempt to evaluate the acceptance of hotel guests (in totality non-disabled) to stay in a DFF, we conducted a survey over a two-month period (from the first of May till the end of June 2016) on arrivals at time of check-in. Two hotels have assisted in this survey through their front-desk employees who asked arrivals at time of check-in whether they mind staying in a DFF. The results were surprising as $92.2 \%$ of the 2021 respondents didn't mind staying in a DFF, what defeats the impression that non-disabled guests will refuse to stay in a DFF.

The choice of Mövenpick Hotel Beirut and Lancaster Plaza Hotel in Beirut for this study was due to:

- Both have a number of disabled friendly facilities.

- Both are five-star hotels.

- Both hotels are large and regularly frequented, what facilitates the collection of data in a short time.

The findings of the survey have shown that only 119 of the 2021 respondents (5.9\%) from both hotels refused to stay in a DFF (see table 2). This indicates that hotel guests of different nationalities, races, origin and age consider a DFF as a regular room and do not mind staying in it. These guests, even if they are not staying in a DFF, are staying in a hotel facility where the overall layout and design allows accessibility for disabled guests.

As for the cross-tab results, 419 out of 466 respondents (90\%) from the Lancaster Plaza hotel and 1445 out of 1555 respondents (93\%) from Mövenpick hotel have accepted to stay in a DFF, which represents approximately the same high percentage (see table 3). As for those who refused to stay in a DFF, they represent approximately 6\% in both hotels. It is relevant to note here that the viability of these results has been tested using Person test which revealed a 0.026 standard error in the rejection of the null hypothesis (see table 4).

Based on these results, providing a number of DFFs should be considered as an openness to a new market (disabled market) that, on the first hand, does not affect the satisfaction of the definite market (regular guests) and, on the other hand, guarantees a minimum economic profit.

Table 2. Do you accept to stay in a DFF?

\begin{tabular}{lrrrr}
\hline & Frequency & Percent & Valid & Percent \\
\hline Valid yes & 1864 & 92.2 & 92.2 & 92.2 \\
No & 119 & 5.9 & 5.9 & 98.1 \\
May be & 22 & 1.1 & 1.1 & 99.2 \\
No answer & 16 & .8 & .8 & 100.0 \\
Total & 2021 & 100.0 & 100.0 &
\end{tabular}

As shown in table 2, only 119 of the 2021 respondents (5.9\%) from both hotels refused to stay in a DFF.

Table 3. Do you accept to stay in a DFF? * Hotel name Cross-tabulation (count)

\begin{tabular}{l|c|c|c|c}
\hline & \multicolumn{2}{|c|}{ Hotel name } & \\
\cline { 2 - 4 } & & Lancaster Plaza & Mövenpick & Total \\
\hline Do you accept to stay in a DFF? Yes & 419 & 1445 & 1864 \\
& No & 29 & 90 & 119 \\
& May be & 11 & 11 & 22 \\
& No answer & 7 & 9 & 16 \\
Total & 466 & 1555 & 2021 \\
\hline
\end{tabular}

As shown in table 3,419 out of 466 respondents (90\%) from the Lancaster Plaza hotel and 1445 out of 1555 respondents (93\%) from Mövenpick hotel have accepted to stay in a DFF. 
Table 4. Symmetric Measures

\begin{tabular}{ll|c|c|c|c}
\hline & Value & $\begin{array}{c}\text { Asymp. Std. } \\
\text { Error }\end{array}$ & Approx. T & Approx. Sig. \\
\hline Interval by Interval & Pearson's R & -.068 & .026 & -3.062 & $.002^{\mathbf{c}}$ \\
Ordinal by Ordinal & Spearman Correlation & -.050 & .024 & -2.230 & $.026^{\mathbf{c}}$ \\
$\mathrm{N}$ of Valid Cases & 2021 & & & \\
\hline
\end{tabular}

a. Not assuming the null hypothesis.

b. Using the asymptotic standard error assuming the null hypothesis.

c. Based on normal approximation.

As shown in table 4, Person test revealed a 0.026 standard error in the rejection of the null hypothesis.

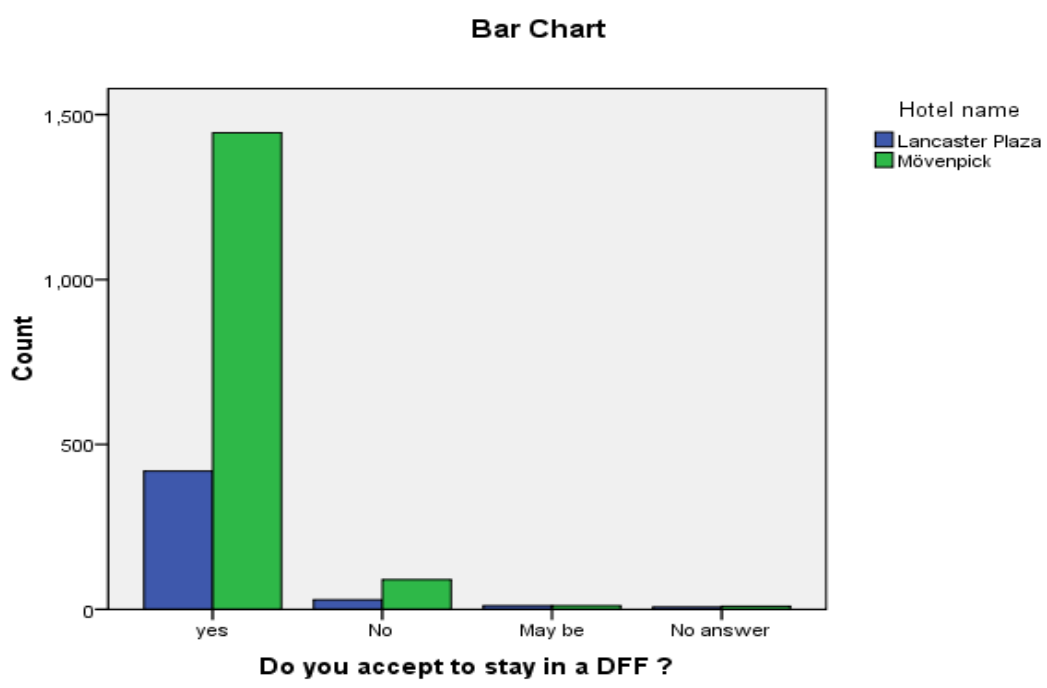

Figure 4. Chart of Statistical Count

\section{Conclusion}

Despite the international recognition of the rights of disabled persons for accessibility to public and private facilities, these rights are vanished in Lebanon due to the deficiency of protecting laws and the lenience of concerned ministries in applying these laws. Especially, the presidential decree law number 7194/2011.

This unpleasant situation has encouraged most hotel owners to disregard the law, justifying their decision by the unnecessary supplementary investments in a DFF, as well as, by the potential risk of losing regular guests due to changes in hotel layout and design.

This paper came to justify the convenience of a DFF, from a financial and an economic perspective, to hotel owners. The convenience that was determined, based on the concepts of ROI; Price Differential; Supply \& Demand and Marginal Revenue, helped us to formulate the relationship between: 1/ the number of DFFs that should be provided, $2 /$ the value of the necessary overall investment, and $3 /$ the required contribution margin.

Furthermore, this study has included the concept of Opportunity Cost in the calculation of profit and suggested an equation for Economic Profit that hotel owners are invited to adopt in the calculation for the economic convenience of a DFF. In conclusion, both the financial and economic parts of this study have justified that a DFF is convenient for hotel owners as it assures a fair return on investment in the presence of sufficient demand.

In parallel, the market survey conducted in this study has proven that the provision of a DFF, as part of a diversification strategy, would enable hotel investors to access a new market whose demand, when added to the demand of regular guests, will assure profitability without sacrificing regular guests' satisfaction and hotel popularity.

Finally, whether the presidential decree law number 7194/2011is sufficient or not, one should be convinced about the feasibility of a DFF from a financial, an economic and a marketing perspective. This study has proven the convenience of a DFF for hotel owners in Lebanon, the lesson is in the application. 


\section{Reference}

AHRC. (2012). Mental or Physical Disabilities and Discrimination. Alberta: Alberta Human Rights Commission.

Anderson, B. (2013, 8 15). Report shows disability law not being enforced. Retrieved from The Daily Star: http://www.dailystar.com.lb/News/Lebanon

BLOM. (2016, July 8). CRO. (I. Baghdadi, Interviewer).

Brennan, J. (2013). The ADA National Network Disability Law Handbook. Texas: Southwest ADA Center.

Case, Fair, \& Oster. (2007). Principles of economics (9 ed.). New Jersey: Pearson Prentice Hall.

Connolly, M. (2004). Townshend-Smith on Discrimination Law: Text, Cases and Materials. London: Cavendish Publishing limited.

Fisher, W. (2007). When should we permit differential pricing of information? UCLA Law Review, 55.

Guinan, J. (2009). Investopedia's Guide To Wall Speak. New York: McGraw-Hill Companies.

Hausman, D. (2015). Valuing Health, Well-being, Freedom and Suffering. New York: Oxford University Press.

Jonita Davis, D. M. (2012, 6 2). Types of Rooms in Hotels. Retrieved april 4, 2015, from travel tips USA: http://traveltips.usatoday.com

Keat, P., \& Young, P. (2009). Managerial Economics. New Jersey: Pearson Prentice Hall.

Michelman, F. (1967). Property, Utility, and Fairness: Comments on the ethical foundations of "Just Compensation Law". Harvard Law Review, 80.

MOT. (2010, 7 9). Ministry of Tourism. Retrieved 3 29, 2015, from Lebanon Ministry of Tourism: http://www.mot.gov.lb/

Raif, E. (2011, 5 22). Persons with Disabilities in an Environment That Does not Respect Their Needs. Retrieved from LPHU: www.lphu.com/

Scott, D. (2003). Wall Street Words: An A to Z Guide to Investment Terms for Today's Investor. Boston: Houghton Mifflin.

UNESCO. (2013, April 2). Social and Human Science. Retrieved from UNESCO: www.unesco.org

Veritas, B. (2015, 11 5). Bureau Veritas Group. Retrieved 3 29, 2015, from Bureau Veritas: http://www.bureauveritas.com

Wau. (2015, March 8). Disability of Persons with Disabilities: Concerns and Obstacles. Wau Magazine(29-30), p. 8.

Yoh, T., Mohr, M., \& Gordon, B. (2008). Assessing Satisfaction with Campus Recreation Facilities Among College Students with Physical Disabilities. Recreation Sports Journal, 32(2), 106-113. 


\section{Appendix1: Hotel classification Criteria}

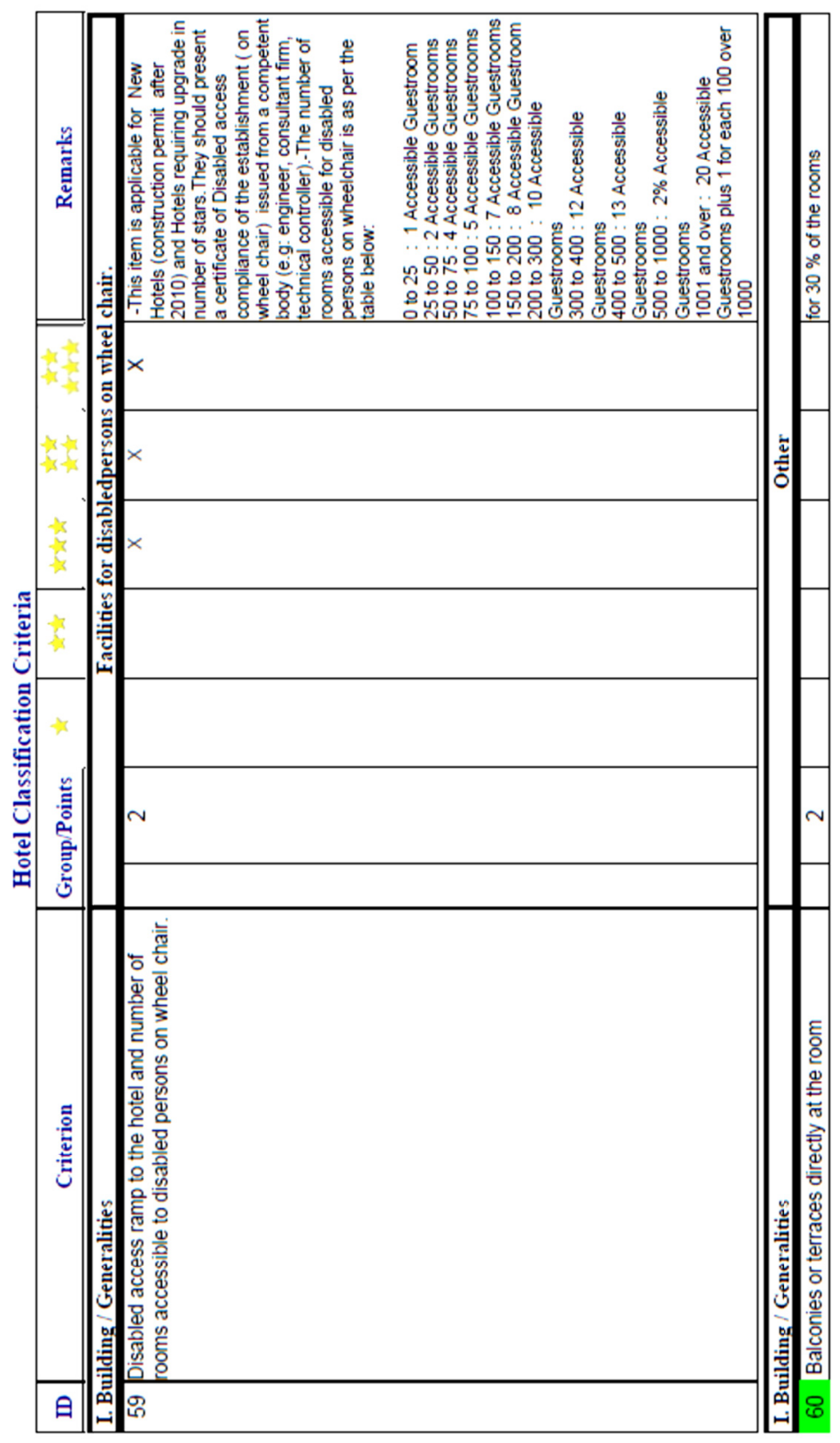

\section{Copyrights}

Copyright for this article is retained by the author(s), with first publication rights granted to the journal.

This is an open-access article distributed under the terms and conditions of the Creative Commons Attribution license which permits unrestricted use, distribution, and reproduction in any medium, provided the original work is properly cited. 